Article

\title{
Novel Fast Chromatography-Tandem Mass Spectrometric Quantitative Approach for the Determination of Plant-Extracted Phytosterols and Tocopherols
}

\author{
George Gachumi ${ }^{1}\left(\mathbb{D}\right.$, Alice Demelenne ${ }^{2}\left(\mathbb{D}\right.$, Asmita Poudel ${ }^{1}$, Zafer Dallal Bashi ${ }^{1}$ and Anas El-Aneed ${ }^{1, *(\mathbb{D}}$ \\ 1 Drug Design and Discovery Group, College of Pharmacy and Nutrition, University of Saskatchewan, \\ Saskatoon, SK S7N 5E5, Canada; george.gachumi@usask.ca (G.G.); asp170@mail.usask.ca (A.P.); \\ zafer.bashi@usask.ca (Z.D.B.) \\ 2 Laboratory for the Analysis of Medicines, Department of Pharmacy, CIRM, University of Liège, \\ 4000 Liege, Belgium; alice.demelenne@uliege.be \\ * Correspondence: anas.el-aneed@usask.ca
}

\section{check for} updates

Citation: Gachumi, G.; Demelenne, A.; Poudel, A.; Dallal Bashi, Z.;

El-Aneed, A. Novel Fast

Chromatography-Tandem Mass Spectrometric Quantitative Approach for the Determination of Plant-Extracted Phytosterols and Tocopherols. Molecules 2021, 26, 1402. https://doi.org/10.3390/

molecules26051402

Academic Editor: Giorgio Marrubini

Received: 3 February 2021

Accepted: 2 March 2021

Published: 5 March 2021

Publisher's Note: MDPI stays neutral with regard to jurisdictional claims in published maps and institutional affiliations.

Copyright: (c) 2021 by the authors. Licensee MDPI, Basel, Switzerland. This article is an open access article distributed under the terms and conditions of the Creative Commons Attribution (CC BY) license (https:/ / creativecommons.org/licenses/by/ $4.0 /)$.

\begin{abstract}
Phytosterols and tocopherols are commonly used in food and pharmaceutical industries for their health benefits. Current analysis methods rely on conventional liquid chromatography, using an analytical column, which can be tedious and time consuming. However, simple, and fast analytical methods can facilitate their qualitative and quantitative analysis. In this study, a fast chromatography-tandem mass spectrometric (FC-MS/MS) method was developed and validated for the quantitative analysis of phytosterols and tocopherols. Omitting chromatography by employing flow injection analysis-mass spectrometry (FIA-MS) failed in the quantification of target analytes due to analyte-to-analyte interferences from phytosterols. These interferences arise from their ambiguous MS fingerprints that would lead to false identification and inaccurate quantification. Therefore, a C18 guard column with a $1.9 \mu \mathrm{m}$ particle size was employed for FC-MS/MS under isocratic elution using acetonitrile/methanol $(99: 1 v / v)$ at a flow rate of $600 \mu \mathrm{L} / \mathrm{min}$. Analyte-to-analyte interferences were identified and eliminated. The false peaks could then be easily identified due to chromatographic separation. In addition, two internal standards were evaluated, namely cholestanol and deuterated cholesterol. Both internal standards contributed to the observed analyte-to-analyte interferences; however, adequate shift in the retention time for deuterated cholesterol eliminated its interferences and allowed for an accurate quantification. The method is fast $(1.3 \mathrm{~min})$ compared to published methods and can distinguish false peaks observed in FIA-MS. Seven analytes were quantified simultaneously, namely brassicasterol, campesterol, stigmasterol, $\beta$-sitosterol, $\alpha$-tocopherol, $\delta$-tocopherol, and $\gamma$-tocopherol. The method was successfully applied in the quantitative analysis of phytosterols and tocopherols present in the unsaponifiable matter of canola oil deodorizer distillate (CODD). $\beta$-sitosterol and $\gamma$-tocopherol were the most abundant phytosterols and tocopherols, respectively.
\end{abstract}

Keywords: phytosterols; tocopherols; fast chromatography-mass spectrometry; canola deodorizer distillate

\section{Introduction}

Phytosterols are plant derived sterols with established cholesterol lowering properties, while tocopherols possess vitamin E activity and act as natural antioxidants [1-3]. Due to these health benefits, their incorporation in functional foods is approved by the U.S Food and Drug Administration (FDA) and Commission Regulation (EU) [4,5], and are commonly used as dietary supplements and food additives. The composition and abundance of phytosterols and tocopherols vary among various plant sources but are widely obtained from vegetable oils, such as soybean, canola, palm, sunflower, corn, and olive oils $[6,7]$. Phytosterols and tocopherols are part of the unsaponifiable matter. They are 
isolated in pure form via the application of various purification techniques such as liquidliquid extraction, solid phase extraction or crystallization [8-10]. Abundant phytosterols in vegetable oils are $\beta$-sitosterol, campesterol, stigmasterol, and brassicasterol (unique in brassica oils, such as rapeseed oil), and four isoforms of tocopherols, namely alpha $(\alpha)$, beta $(\beta)$, gamma $(\gamma)$, and delta $(\delta)$ (Figure 1$)$. Consumers have become health-conscious, driving the demand for natural bioactives relative to their synthetic counterparts. Consequently, the use of natural products as food additives is favored. Regardless of the source for the bioactives, a fast, simple, and sensitive analytical method is required for their identification and quantification [11,12]. Traditionally, gas chromatography (GC) with flame ionization detector (FID) [13-17] or mass spectrometry (MS) [18-21] has been utilized for the determination phytosterols and tocopherols. However, derivatization of analytes is usually required in GC to improve analytes' volatility, thermal stability, and sensitivity [22]. Despite its separation capability including the ability to resolve structural isomers [22,23], GC is laborious, requiring long run time and is not ideal for routine analysis.
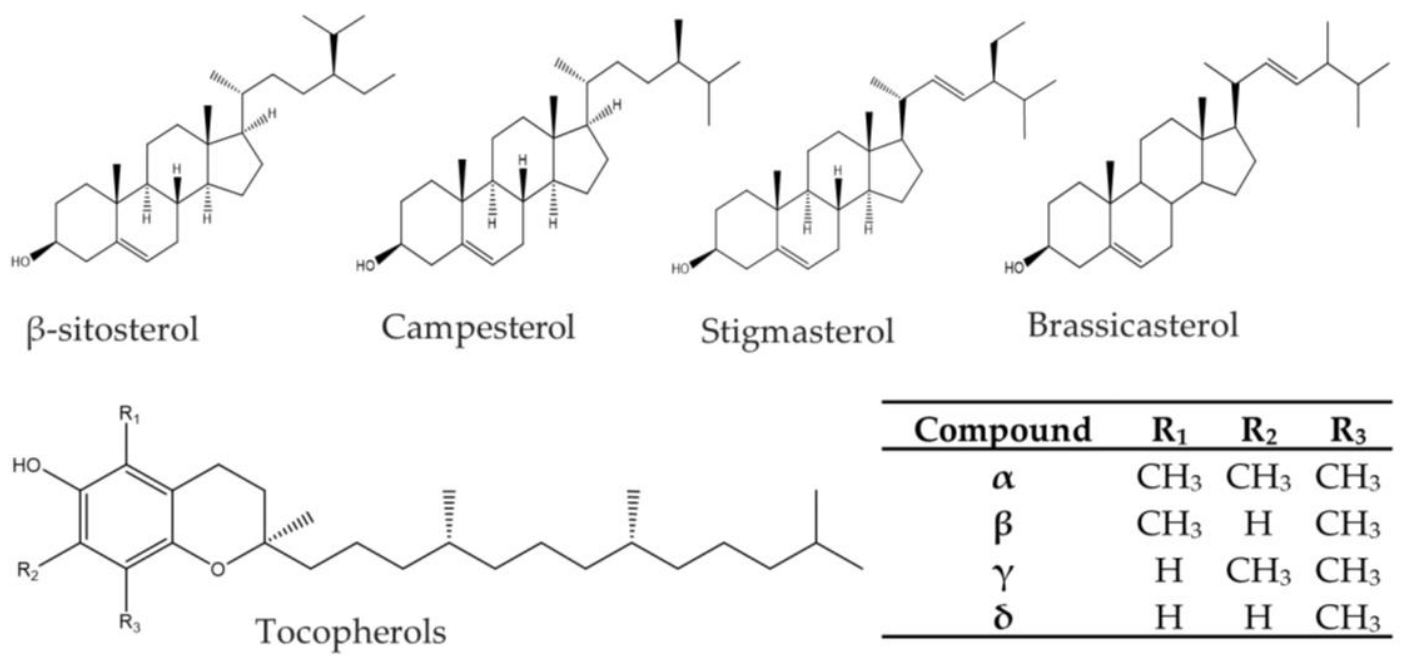

Figure 1. Structures of abundant phytosterols and tocopherols ( $\alpha$-alpha, $\beta$-beta, $\gamma$-gamma, and $\delta$-delta).

To avoid derivatization, liquid chromatography-mass spectrometry (LC-MS) has been adapted. Ionization at atmospheric pressure is employed and both electrospray ionization (ESI) and atmospheric pressure chemical ionization (APCI) have been used for the analysis of phytosterols and tocopherols [24-26]. Although tocopherols ionize efficiently in both ESI and APCI, phytosterols ionize better using APCI [27-29]. Phytosterols primarily ionize as $\left[\mathrm{M}+\mathrm{H}-\mathrm{H}_{2} \mathrm{O}\right]^{+}$ion while $[\mathrm{M}+\mathrm{H}]^{+}$and $[\mathrm{M}+\mathrm{H}-4 \mathrm{H}]^{+}$appear as minor ions in both APCI and ESI $[30,31]$. Tocopherols, on the other hand, ionize in APCI as the protonated species $[\mathrm{M}+\mathrm{H}]^{+}$as well as the molecular ion $[\mathrm{M}]^{+}[32-34]$. Both normal phase (NP) and reversed phase (RP) chromatography have been used for the analysis of phytosterols and tocopherols. The former showed better separation, particularly the ability to resolve the structural isomers, $\beta$ and $\gamma$-tocopherols [15]. However, the introduction of columns that combine hydrophobic, charge transfer, and $\pi-\pi$ interactions such as pentafluorophenyl (PFP) have enabled the application of RP-LC that shows baseline separation of the four tocopherol isoforms [35,36].

Numerous LC-MS methods have been developed for the analysis of phytosterols [37,38], tocopherols [35,36], or their combined mixture [24,34]. Simultaneous determination of phytosterols and tocopherols is ideal when the two group of analytes should be quantified as it simplifies the analytical procedure. Recently, we developed LC-MS quantification and screening methods for the simultaneous analysis of phytosterols and tocopherols with an analysis run time of $6.5 \mathrm{~min}[39,40]$. An alternative strategy for fast quantitative analysis is flow injection analysis (FIA)-MS, that involves the omission of the analytical column, 
provided that the robustness of quantification is not compromised [41-43]. Although "separation" in case of FIA-MS relies on the high selectivity of MS, such ability is lost when more than one analyte shares the exact precursor ion (e.g., isomers, isobars) in the single ion monitoring (SIM) mode or have similar transitions when employing multiple reaction monitoring (MRM). In fact, quantitative FIA-MS is commonly reported for one or two analytes and is challenging when analyzing multiple targets [44]. FIA-MS is, therefore, not generally suitable for the analysis of isomers or structurally similar compounds as selectivity is compromised. MS suffers from analyte-to-analyte interferences that result in ions with similar $m / z$ value or mass transitions with identical product ions. These interferences in FIA-MS originate from in-source fragmentations and they can undermine the analytical results $[45,46]$. However, they can be easily identified by analyzing pure individual reference standards [47].

Analyte-to-analyte interferences for phytosterols have already been reported (supplementary materials Table S1). For example, during MS analysis, campesterol, which was monitored at $m / z 383$ as $\left[\mathrm{M}+\mathrm{H}-\mathrm{H}_{2} \mathrm{O}\right]^{+}$ion, also produced during ionization two ions at $m / z 395$ and 397 that matches the $\left[\mathrm{M}+\mathrm{H}-\mathrm{H}_{2} \mathrm{O}\right]^{+}$of stigmasterol and sitosterol, respectively. Similarly, sitosterol, which was monitored at $m / z 397$ as $\left[\mathrm{M}+\mathrm{H}-\mathrm{H}_{2} \mathrm{O}\right]^{+}$ ion, produced an ion at $m / z 409$ that have the same $\mathrm{m} / \mathrm{z}$ value of $\left[\mathrm{M}+\mathrm{H}-\mathrm{H}_{2} \mathrm{O}\right]^{+}$of cycloartenol [48]. Naoyuki Ishida reported the monitoring of stigmasterol $[\mathrm{M}+\mathrm{H}-4 \mathrm{H}]^{+}$ at $m / z 409.4$ instead of [M $\left.+\mathrm{H}-\mathrm{H}_{2} \mathrm{O}\right]^{+}$at $m / z 395.4$ due to peak overlap (interference) with campesterol [49]. Despite reporting these interferences, the exact structures for the various interfering ions was never fully elucidated with few studies hypothesizing that they arise from either dehydrogenation or cyclization of the parent compound [50,51]. Unlike phytosterols, no interferences have been reported during the analysis of tocopherols.

To achieve fast analysis without compromising selectivity, fast chromatography (FC), using a guard column only, can allow for sufficient separation in a short time in comparison to conventional chromatography (using an analytical column) [44,52]. In this study, we report for the first time, the development of a FC-MS/MS method for the simultaneous analysis of phytosterols and tocopherols with a total run time of $1.3 \mathrm{~min}$. In addition, the ambiguous MS fingerprints of phytosterols and how they contribute to analyte-to-analyte interferences were identified, discussed and eliminated. Although the intrinsic capabilities of mass spectrometer can be employed in analysis, understanding the MS fingerprints of analytes is crucial. The reported work provides novel strategies for measuring target analytes and expands the knowledge base regarding the reliance on the intrinsic capabilities of mass spectrometer for validated quantitative analysis.

\section{Results and Discussion}

\subsection{Method Development}

We previously developed and reported LC-APCI-MS/MS method for the simultaneous analysis of phytosterols and tocopherols, including their ionization and fragmentation behavior $[39,40]$. Analyte-to-analyte interferences amongst phytosterols were identified; however, due to the use of conventional chromatography with an analytical column, they did not interfere with identification and quantification. Chromatographic separation of the analytes, allowed for identification and quantification, despite the presence of interfering peaks at different retention times. To the best of our knowledge, no current study has succinctly explained the analyte-to-analyte interferences and their effects during the analysis of phytosterols. Understanding these interferences will allow for the development of rapid analytical methods, such as FIA- or FC-MS that can substantially reduce the analysis time. In this work, the sources of interferences were identified as the minor ions $[\mathrm{M}+\mathrm{H}-2 \mathrm{H}]^{+}$ and $[\mathrm{M}+\mathrm{H}-4 \mathrm{H}]^{+}$(Table 1 ). These interfering ions matches the $m / z$ value of another analyte monitored as $\left[\mathrm{M}+\mathrm{H}-\mathrm{H}_{2} \mathrm{O}\right]^{+}$. For example, brassicasterol which is monitored at $m / z 381$ as $\left[\mathrm{M}+\mathrm{H}-\mathrm{H}_{2} \mathrm{O}\right]^{+}$will also ionize as $[\mathrm{M}+\mathrm{H}-4 \mathrm{H}]^{+}$at $m / z 395$ which is the same $m / z$ value for the $\left[\mathrm{M}+\mathrm{H}-\mathrm{H}_{2} \mathrm{O}\right]^{+}$ion for stigmasterol, while campesterol which is monitored at $m / z 383$ as $\left[\mathrm{M}+\mathrm{H}-\mathrm{H}_{2} \mathrm{O}\right]^{+}$will also ionize as $[\mathrm{M}+\mathrm{H}-4 \mathrm{H}]^{+}$at $m / z 397$ 
which is the same $m / z$ value for the $\left[\mathrm{M}+\mathrm{H}-\mathrm{H}_{2} \mathrm{O}\right]^{+}$ion for $\beta$-sitosterol (Table 1). Thus, brassicasterol ionization produces a "false" stigmasterol peak while campesterol ionization yields a "false" $\beta$-sitosterol peak.

Table 1. Observed analyte-to-analyte interferences amongst phytosterols due to the presence of other minor ions.

\begin{tabular}{|c|c|c|c|c|}
\hline Compound & Molecular Weight & 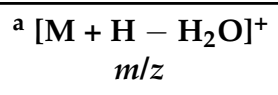 & $\begin{array}{c}{[\mathrm{M}+\mathrm{H}-4 \mathrm{H}]^{+}} \\
m / z\end{array}$ & $\begin{array}{c}{[\mathbf{M}+\mathbf{H}-2 \mathbf{H}]^{+}} \\
m / z\end{array}$ \\
\hline Stigmasterol & 412.7 & $\underline{395}$ & 409 & 411 \\
\hline Brassicasterol & 398.7 & 381 & $\underline{395}$ & 397 \\
\hline$\beta$-sitosterol & 414.7 & 397 & 411 & 413 \\
\hline Campesterol & 400.7 & 383 & 3997 & 399 \\
\hline Cholestanol (IS) & 388.7 & 371 & 385 & 387 \\
\hline $\mathrm{d}_{6}$-cholesterol (IS) & 392.7 & 375 & 389 & 391 \\
\hline
\end{tabular}

${ }^{\mathrm{a}}\left[\mathrm{M}+\mathrm{H}-\mathrm{H}_{2} \mathrm{O}\right]^{+}$is the ion used for quantification.

Although the ion designated $[\mathrm{M}+\mathrm{H}-2 \mathrm{H}]^{+}$was also observed for all the reference standards, only the ion $[\mathrm{M}+\mathrm{H}-4 \mathrm{H}]^{+}$contributed to the observed interferences when $[\mathrm{M}$ $\left.+\mathrm{H}-\mathrm{H}_{2} \mathrm{O}\right]^{+}$is selected as the precursor ion in the MRM mode. In addition, cholestanol, phytosterols' internal standard (IS) also contributed interfering ions for brassicasterol at $m / z 381 \rightarrow 147$ and campesterol at $m / z 383 \rightarrow 161$ and $383 \rightarrow 147$ (Supplementary materials Figure S1). The formation of such ions from the IS is unclear since they did not arise from the corresponding minor ions $[\mathrm{M}+\mathrm{H}-2 \mathrm{H}]^{+}$and $[\mathrm{M}+\mathrm{H}-4 \mathrm{H}]^{+}$(Table 1). All the identified minor ions are structurally distinct from that of the actual compound; however, the MS/MS fragmentation patterns are similar. The monitored ion $\left[\mathrm{M}+\mathrm{H}-\mathrm{H}_{2} \mathrm{O}\right]^{+}$and the corresponding interfering minor ions with the same $m / z$ value show similar product ions and cannot be differentiated (Supplementary Materials Figures S2-S4). Thus, even when a different product ion is selected, the interferences are not eliminated due to the similarities in product ions of the actual compound and those from minor ions. It should be noted that the interfering ion in case of the IS is not seen at the retention time of the campesterol in case of LC-MS [39] indicating that it is not a contamination within the IS itself.

When FIA-MS/MS is employed for the simultaneous analysis of phytosterols and tocopherols, erroneous identification and quantification of phytosterols are observed due to the interferences described above. The MRM transitions of the monitored target compounds and those from interferences are identical and this issue can only be resolved by utilizing some level of chromatographic separation; hence, we adopted the fast chromatography approach as discussed below.

\subsubsection{Fast Chromatography (FC)}

To address the issue of analyte-to-analyte interferences for phytosterols and maintain a fast analysis time, the use of a guard column is evaluated. The goal is to achieve sufficient chromatographic separation that can differentiate the signal for the analyte of interest from the interfering signal.

A C18 poroshell guard column $(2.1 \mathrm{~mm} \times 5 \mathrm{~mm}, 2.7 \mu \mathrm{m})$ was used and its performance was evaluated based on its ability to distinctly resolve the peaks of interest from interfering peaks. An isocratic elution with acetonitrile/methanol 99:1 $(v / v)$ was employed at a flow rate of $200 \mu \mathrm{L} / \mathrm{min}$. In addition, column temperature was varied between $10-20^{\circ} \mathrm{C}$ with better separation achieved at $10^{\circ} \mathrm{C}$, and this was applied throughout the analysis. The total run time at the optimized condition was $2 \mathrm{~min}$. Although enough separation was achieved to differentiate the interfering peaks, brassicasterol and campesterol coeluted closely with cholestanol (IS) (Figure 2A). As already mentioned, this IS contributed to interferences for both campesterol and brassicasterol. At low concentrations, these interfering peaks were apparent as a shoulder peak; however, at higher concentrations they were completely merged with the analyte of interest thereby compromising the analytical results (Supple- 
mentary materials Figure S5). In fact, in the presence of internal standard cholestanol, campesterol cannot be resolved.
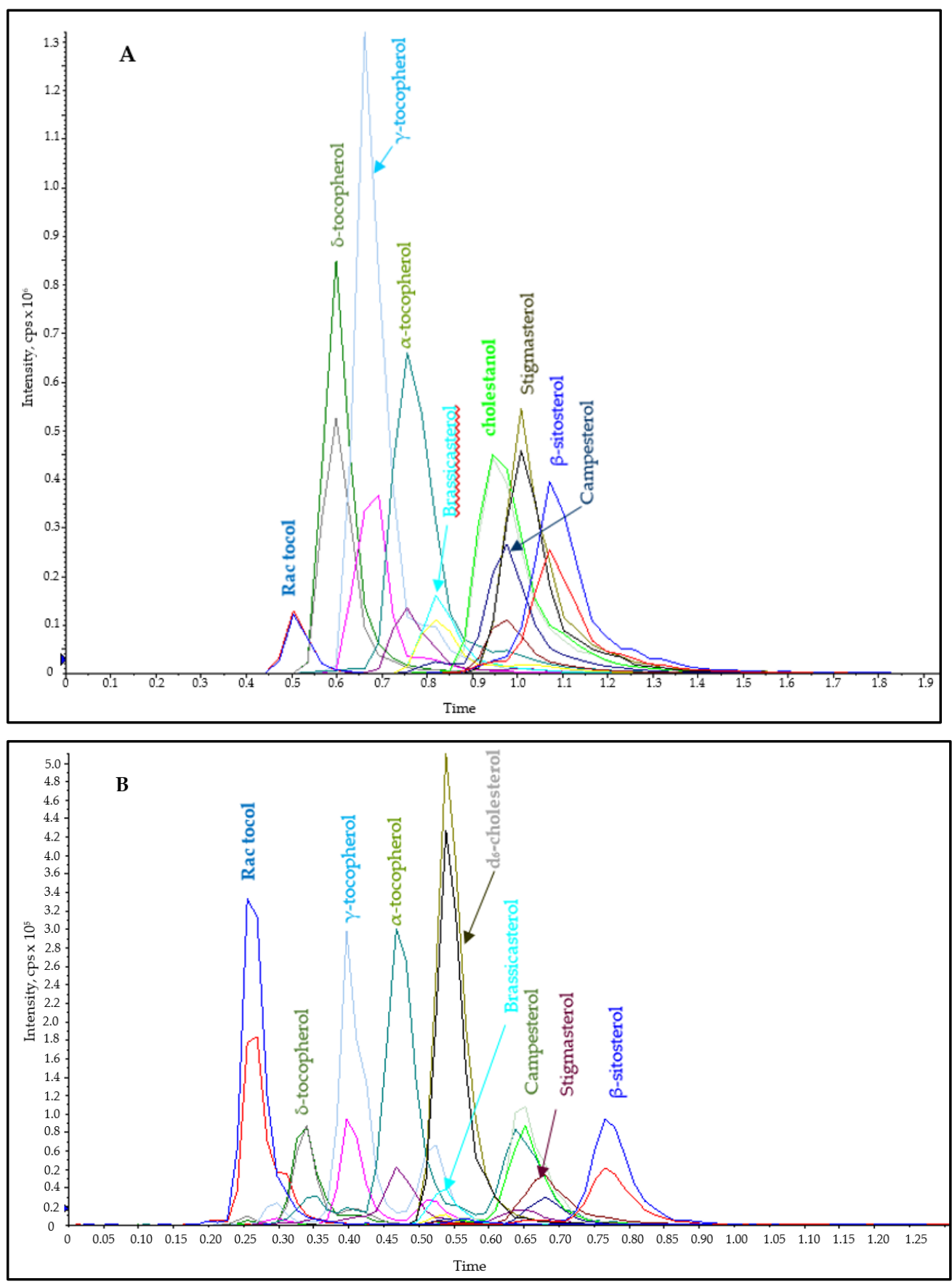

Figure 2. FC-MS/MS chromatogram of phytosterols and tocopherols on (A) $2.7 \mu \mathrm{m}$ guard column at $200 \mu \mathrm{L} / \mathrm{min}$ and (B) $1.9 \mu \mathrm{m}$ guard column at $600 \mu \mathrm{L} / \mathrm{min}$. Better separation of analytes including the interfering ions was achieved by using $1.9 \mu \mathrm{m}$ guard column.

To address the interference from cholestanol, the IS was substituted with another compound, namely deuterated cholesterol $\left(\mathrm{d}_{6}\right)$ (Table 1 ). However, $\mathrm{d}_{6}$-cholesterol contributed to the formation of an interfering peak that matches campesterol (Supplementary materials Figure S6) and since they closely coeluted, the interfering peak could not be differentiated as it merged with the actual peak for campesterol. As explained earlier about 
cholestanol interfering peaks, $\mathrm{d}_{6}$-cholesterol interfering ion does not match $[\mathrm{M}+\mathrm{H}-2 \mathrm{H}]^{+}$ or $[\mathrm{M}+\mathrm{H}-4 \mathrm{H}]^{+}$and it possibly arise via a different ionization mechanism.

Further improvements in chromatographic separation are, therefore, needed to address the interference observed from the IS. Chromatographic separation relies on column efficiency, a factor expressed as theoretical plates or height equivalent theoretical plates $(\mathrm{H})$ when normalized with column length [53]. Thus, the more efficient a column is, the smaller is the $\mathrm{H}$ term. Stationary phase particle size and morphology are known to play a key role in increasing theoretical plates (equivalent to low $\mathrm{H}$ ) [54]. To this end, the guard column length had to be maintained for short analysis time and seek a stationary phase of smaller particle size for improved column efficiency. A poroshell C18 guard column with smaller particle size of $1.9 \mu \mathrm{m}$ was, therefore, tested. The chromatographic conditions were the same as optimized for the $2.7 \mu \mathrm{m}$ guard column, except for the flow rate which was $600 \mu \mathrm{L} / \mathrm{min}$ and the total run time was $1.3 \mathrm{~min}$.

The results showed a significant improvement when compared to the guard column with a $2.7 \mu \mathrm{m}$ particle size (Figure 2B). Efficient separation was achieved for all compounds except two pairs that coeluted, namely $\mathrm{d}_{6}$-cholesterol/brassicasterol, and campesterol/stigmasterol. However, since the monitored MRMs are different, method selectivity and sensitivity were attained. In fact, $\mathrm{d}_{6}$-cholesterol eluted closely with campesterol and the interfering peak was resolved even at high concentrations (Supplementary materials Figure S7). The use of a guard column with $1.9 \mu \mathrm{m}$ particle size was, therefore, ideal for the simultaneous analysis of phytosterols and tocopherols.

\subsubsection{MS Conditions}

The ion source and compound dependent parameters were optimized through direct infusion as already reported [39]. Phytosterols ionized as $\left[\mathrm{M}+\mathrm{H}-\mathrm{H}_{2} \mathrm{O}\right]^{+}$, whereas tocopherols showed abundant molecular ion $\mathrm{M}^{\cdot+}$. For quantification, the MRM mode was selected, and two transitions were monitored for each analyte, quantifier and a qualifier ion (Table 2).

Table 2. The mass transitions, collision energy (CE), and retention times of all target compounds including the internal standards. Declustering potential (DP) of $40 \mathrm{~V}$ was applied to all analytes.

\begin{tabular}{|c|c|c|c|c|c|}
\hline \multicolumn{2}{|c|}{ Compound } & $\begin{array}{l}\text { Retention Time } \\
\text { (min) }\end{array}$ & $\begin{array}{l}\text { Precursor Ion } \\
(\mathrm{m} / \mathrm{z})\end{array}$ & $\begin{array}{l}\text { MRM Transitions } \\
\qquad(m / z)\end{array}$ & CE (V) \\
\hline \multirow{4}{*}{ Phytosterols } & Brassicasterol & 0.50 & 381.4 & $\begin{array}{l}297.4 \\
147.1\end{array}$ & $\begin{array}{l}22 \\
30\end{array}$ \\
\hline & Campesterol & 0.61 & 383.4 & $\begin{array}{l}161.1 \\
147.1\end{array}$ & $\begin{array}{l}30 \\
30\end{array}$ \\
\hline & Stigmasterol & 0.63 & 395.4 & $\begin{array}{c}297.4 \\
83.2\end{array}$ & $\begin{array}{l}23 \\
26\end{array}$ \\
\hline & $\beta$-Sitosterol & 0.73 & 397.4 & $\begin{array}{l}161.2 \\
134.9\end{array}$ & $\begin{array}{l}27 \\
28\end{array}$ \\
\hline \multirow{3}{*}{ Tocopherols } & Delta Tocopherol $(\delta)$ & 0.32 & 402.4 & $\begin{array}{l}177 \\
137\end{array}$ & $\begin{array}{l}32 \\
38\end{array}$ \\
\hline & Gamma Tocopherol $(\gamma)$ & 0.38 & 416 & $\begin{array}{l}151.1 \\
191.2\end{array}$ & $\begin{array}{l}37 \\
34\end{array}$ \\
\hline & Alpha Tocopherol $(\alpha)$ & 0.44 & 430 & $\begin{array}{l}165.3 \\
205.2\end{array}$ & $\begin{array}{l}38 \\
36\end{array}$ \\
\hline \multirow{3}{*}{ Internal Standards } & $\mathrm{D}_{6}$-Cholesterol & 0.51 & 375.4 & $\begin{array}{l}152 \\
167\end{array}$ & $\begin{array}{l}30 \\
28\end{array}$ \\
\hline & Cholestanol & 0.95 & 371.4 & $\begin{array}{c}95 \\
109\end{array}$ & $\begin{array}{l}32 \\
30\end{array}$ \\
\hline & Rac Tocol & 0.26 & 388.4 & $\begin{array}{c}163.2 \\
122\end{array}$ & $\begin{array}{l}30 \\
40\end{array}$ \\
\hline
\end{tabular}


Dwell time, the time needed for acquiring a specific MRM during each cycle can affect the quantitative data. High dwell time is normally desirable for better signal-tonoise ratio; however, it becomes impractical to assign high dwell times for multi analytes coeluting when a short analysis time is desired. A scheduled MRM (sMRM) approach was, therefore, adapted. sMRM algorithm automatically adjusts the dwell time of each compound depending on user defined target scan time $\left(t_{\text {Target }}\right)$. Optimization of $t_{\text {Target }}$ was conducted with an aim of achieving at least 10 data points and $t_{\text {Target }}$ values of $0.3-$ $0.6 \mathrm{~s}$ were tested. $\mathrm{A}_{\text {Target }}$ of $0.3-0.4 \mathrm{~s}$ allowed for acquiring more data points but it led to distorted chromatographic peak shape, while values above $0.6 \mathrm{~s}$ did not provide the minimum number of 8 data points across the chromatographic peak. Therefore, a value of $0.55 \mathrm{~s}$ was optimal since it allowed for the acquisition of the minimum data points with good peak shapes (Figure 2B). To further enhance the reproducibility of the method, MRM detection window was also optimized. This window is an estimate of the chromatographic peak width and its value should also accommodate any chromatographic shifts. An MRM detection window of $35 \mathrm{~s}$ was optimal, and it was based on the chromatographic peak with largest peak width.

\subsection{Method Validation}

The method validation was conducted following the International Council for Harmonization of Technical Requirements for Pharmaceuticals for Human Use (ICH) guidelines [55], and included linearity, sensitivity, accuracy, precision, repeatability, matrix effects, and recovery.

\subsubsection{Calibration Range and Sensitivity}

Phytosterols and tocopherols calibration curves were generated by applying a $1 / x$ weighted linear regression analysis in the concentration range $0.05-10 \mu \mathrm{g} / \mathrm{mL}$. Phytosterols showed a linear regression in the range $0.05-10 \mu \mathrm{g} / \mathrm{mL}$ while tocopherols showed linearity in the range of $0.25-10 \mu \mathrm{g} / \mathrm{mL}$ with a correlation coefficients $\left(\mathrm{R}^{2}\right)$ of at least 0.99 for all analytes. The exception, however, were gamma and delta tocopherols that were fitted to a quadratic calibration curve with a $\mathrm{R}^{2}$ of at least 0.99 . A quadratic calibration curve for tocopherols was reported previously [39]. Supplementary Materials Figure S8 shows the calibration curves for phytosterols and tocopherols.

The LLOQ value was chosen as the lowest concentration on the calibration curve with an accuracy and precision value within $\pm 20 \%$ and were, $0.05 \mu \mathrm{g} / \mathrm{mL}$ and $0.25 \mu \mathrm{g} / \mathrm{mL}$ for phytosterols and tocopherols, respectively. Limit of detection (LOD) for all analytes was determined at the lowest detectable concentrations at $S / N \geq 3$. The determined LOD values were $0.005 \mu \mathrm{g} / \mathrm{mL}$ for campesterol and $\beta$-sitosterol, $0.01 \mu \mathrm{g} / \mathrm{mL}$ for $\delta$-tocopherol, brassicasterol, and stigmasterol, and $0.05 \mu \mathrm{g} / \mathrm{mL}$ for $\alpha$ - and $\gamma$-tocopherol. The reported LLOQ values were similar to previously developed LC-MS/MS method [39]. On the other hand, a two-fold decrease in brassicasterol and $\delta$-tocopherol and five-fold decrease in $\alpha$ and $\gamma$-tocopherol were observed while the LOD values remained the same for campesterol, stigmasterol, and sitosterol.

\subsubsection{Intra and Interday Accuracy and Precision}

To establish the repeatability of the developed method, accuracy and precision were evaluated on a single day (intraday) and on three different days (interday) at four QC levels (Table 3). QC samples spiked in the matrix were only monitored for $\delta$-tocopherol (LLOQ, LQC, MQC, and HQC) and stigmasterol (MQC, and HQC) as highlighted in Sections 3.5 and 3.5.2. Four replicates were analyzed at each QC level and all the values were found to be within the acceptable values of accuracy and precision within $\pm 15 \% \mathrm{CV}$ except at LLOQ which can be $\pm 20 \%$ CV for QCs made in neat and those spiked in matrix (Table 3). In fact, over $90 \%$ of the QC samples had precision values within $\pm 5 \% \mathrm{CV}$ from the nominal concentration while the rest were within $\pm 10 \%$. The reported method is developed to measure analytes within vegetable oil samples and the QC samples prepared in the matrix 
in the case of delta tocopherol and stigmasterol are representatives for tocopherols and phytosterols, respectively. We adopted established methodologies for method validation in the case where analyte-free matrix is not available $[56,57]$.

Table 3. Inter-day and intra-day accuracy and precision of phytosterols and tocopherols prepared in surrogate matrix ${ }^{\mathrm{a}}$ and sample matrix ${ }^{\mathrm{b}}(n=4)$.

\begin{tabular}{|c|c|c|c|c|c|c|c|c|c|c|}
\hline \multirow[b]{2}{*}{ Compound $^{a}$} & & \multirow{2}{*}{$\begin{array}{c}\text { Concentration } \\
(\mu \mathrm{g} / \mathrm{mL})\end{array}$} & \multicolumn{2}{|c|}{ Intra-day } & \multicolumn{2}{|c|}{ Inter-day 1} & \multicolumn{2}{|c|}{ Inter-day 2} & \multicolumn{2}{|c|}{ Inter-day 3} \\
\hline & & & $\underset{(\%)}{\text { Accuracy }}$ & $\begin{array}{l}\text { Precision } \\
\text { (\%RSD) }\end{array}$ & $\underset{(\%)}{\text { Accuracy }}$ & $\begin{array}{l}\text { Precision } \\
\text { (\%RSD) }\end{array}$ & $\underset{(\%)}{\text { Accuracy }}$ & $\begin{array}{l}\text { Precision } \\
\text { (\%RSD) }\end{array}$ & $\underset{(\%)}{\text { Accuracy }}$ & $\begin{array}{l}\text { Precision } \\
\text { (\%RSD) }\end{array}$ \\
\hline \multirow{4}{*}{$\delta$-Tocopherol } & LLOQC & 0.25 & 97.83 & 6.06 & 92.86 & 3.96 & 95.05 & 5.42 & 96.85 & 3.45 \\
\hline & LQC & 0.75 & 94.19 & 4.73 & 90.96 & 4.59 & 96.08 & 0.85 & 102.59 & 5.90 \\
\hline & MQC & 5.5 & 101.08 & 1.82 & 94.46 & 3.86 & 96.59 & 2.51 & 95.70 & 1.13 \\
\hline & HQC & 8 & 98.16 & 5.37 & 96.08 & 3.14 & 99.42 & 2.63 & 99.23 & 3.64 \\
\hline \multirow{4}{*}{$\begin{array}{c}\beta / \gamma^{-} \\
\text {Tocopherol }\end{array}$} & LLOQC & 0.25 & 107.29 & 2.93 & 88.74 & 0.72 & 94.80 & 3.68 & 100.43 & 3.22 \\
\hline & LQC & 0.75 & 96.04 & 2.62 & 90.64 & 4.39 & 94.34 & 1.70 & 94.20 & 3.50 \\
\hline & MQQC & 5.5 & 100.00 & 4.97 & 90.30 & 4.32 & 96.68 & 3.86 & 95.67 & 2.35 \\
\hline & HQ̄C & 8 & 98.01 & 2.57 & 90.49 & 3.62 & 99.49 & 1.46 & 100.35 & 2.77 \\
\hline \multirow{4}{*}{$\alpha$-Tocopherol } & LLOQC & 0.25 & 118.38 & 0.49 & 109.49 & 2.32 & 118.32 & 2.29 & 115.59 & 1.70 \\
\hline & LQC & 0.75 & 94.22 & 3.34 & 89.46 & 3.51 & 91.76 & 1.65 & 94.58 & 4.65 \\
\hline & MQC & 5.5 & 104.32 & 2.78 & 92.00 & 2.82 & 95.14 & 2.86 & 99.50 & 1.92 \\
\hline & HQ̄C & 8 & 102.69 & 4.83 & 96.42 & 2.02 & 102.74 & 3.43 & 103.81 & 2.86 \\
\hline \multirow{4}{*}{ Brassicasterol } & LLOQC & 0.05 & 93.91 & 9.66 & 99.01 & 9.66 & 109.43 & 6.81 & 117.57 & 3.43 \\
\hline & LQC & 0.15 & 97.14 & 7.50 & 98.98 & 7.50 & 102.26 & 1.07 & 96.47 & 2.70 \\
\hline & MQC & 5.5 & 96.75 & 1.80 & 96.65 & 1.80 & 97.06 & 3.97 & 95.72 & 0.72 \\
\hline & HQC & 8 & 95.91 & 3.00 & 101.17 & 3.00 & 99.55 & 1.83 & 101.44 & 3.73 \\
\hline \multirow{4}{*}{ Campesterol } & LLOQC & 0.05 & 99.39 & 0.67 & 114.21 & 5.57 & 104.15 & 2.88 & 108.77 & 1.37 \\
\hline & LQC & 0.15 & 101.60 & 3.01 & 106.84 & 3.52 & 10.3 .9 & 0.77 & 102.95 & 2.93 \\
\hline & MQ̄C & 5.5 & 101.77 & 1.68 & 102.33 & 1.37 & 103.91 & 2.95 & 97.43 & 4.10 \\
\hline & HQ̄C & 8 & 97.57 & 1.24 & 102.37 & 5.16 & 101.16 & 3.35 & 98.53 & 2.80 \\
\hline \multirow{4}{*}{ Stigmasterol } & LLOQC & 0.05 & 94.56 & 0.96 & 113.98 & 8.81 & 116.74 & 3.80 & 118.44 & 4.26 \\
\hline & LQC & 0.15 & 94.00 & 3.38 & 103.28 & 6.18 & 103.93 & 1.25 & 102.48 & 2.52 \\
\hline & MQ̄C & 5.5 & 96.72 & 2.47 & 95.68 & 2.42 & 98.97 & 1.82 & 95.05 & 4.09 \\
\hline & HQ̄C & 8 & 94.75 & 2.83 & 97.21 & 6.27 & 98.19 & 4.36 & 95.32 & 3.82 \\
\hline \multirow{4}{*}{$\beta$-Sitosterol } & LLOQC & 0.05 & 99.28 & 2.86 & 108.12 & 3.23 & 103.45 & 5.96 & 110.09 & 3.55 \\
\hline & LQC & 0.15 & 100.18 & 2.65 & 108.53 & 4.56 & 107.89 & 2.88 & 102.19 & 2.36 \\
\hline & MQC & 5.5 & 102.31 & 0.87 & 99.72 & 1.73 & 103.56 & 1.66 & 97.56 & 3.81 \\
\hline & HQC & 8 & 98.92 & 1.82 & 100.75 & 4.24 & 103.31 & 2.94 & 99.01 & 2.95 \\
\hline \multirow[b]{2}{*}{ Compound $^{b}$} & & \multirow{2}{*}{$\begin{array}{c}\text { Concentration } \\
(\mu \mathrm{g} / \mathrm{mL})\end{array}$} & \multicolumn{2}{|c|}{ Intra-Day } & \multicolumn{2}{|c|}{ Inter-Day 1} & \multicolumn{2}{|c|}{ Inter-Day 2} & \multicolumn{2}{|c|}{ Inter-Day 3} \\
\hline & & & $\underset{(\%)}{\text { Accuracy }}$ & $\begin{array}{l}\text { Precision } \\
\text { (\%RSD) }\end{array}$ & $\underset{(\%)}{\text { Accuracy }}$ & $\begin{array}{l}\text { Precision } \\
\text { (\%RSD) }\end{array}$ & $\underset{(\%)}{\text { Accuracy }}$ & $\begin{array}{l}\text { Precision } \\
\text { (\%RSD) }\end{array}$ & $\underset{(\%)}{\text { Accuracy }}$ & $\begin{array}{l}\text { Precision } \\
\text { (\%RSD) }\end{array}$ \\
\hline \multirow{4}{*}{$\delta$-Tocopherol } & LLOQC & 0.25 & 87.4 & 1.08 & 113.57 & 3.84 & 106.18 & 5.49 & 117.17 & 2.23 \\
\hline & LQC & 0.75 & 96.4 & 1.62 & 103.04 & 3.82 & 96.81 & 0.63 & 108.50 & 4.29 \\
\hline & MQC & 5.5 & 94.1 & 1.97 & 97.06 & 1.70 & 106.0 & 1.33 & 97.76 & 5.06 \\
\hline & HQ̄C & 8 & 99.9 & 3.25 & 96.59 & 3.91 & 91.20 & 1.40 & 91.99 & 2.67 \\
\hline \multirow[b]{2}{*}{ Stigmasterol } & MQC & 5.5 & 93.3 & 3.63 & 95.95 & 0.05 & 98.38 & 4.59 & 99.32 & 7.63 \\
\hline & HQC & 8 & 96.5 & 2.42 & 97.11 & 1.94 & 103.02 & 3.91 & 103.37 & 0.87 \\
\hline
\end{tabular}

a Surrogate matrix used was neat solvent (acetonitrile); ${ }^{\mathrm{b}}$ Sample matrix is CODD extract.

\subsubsection{Recovery and Matrix Effects}

Matrix effects were evaluated at both LQC and HQC using $\delta$-tocopherol and stigmasterol. Matrix effects for stigmasterol was only conducted at HQC since its endogenous amount is above the LQC value. Matrix effect for $\delta$-tocopherol at LQC and HQC and stigmasterol at HQC are shown in Table 4. It can be observed that, there is slight ion suppression for $\delta$-tocopherol at HQC and ion enhancement at LQC, and HQC for $\delta$-tocopherol and stigmasterol, respectively. Recovery experiments showed practically no sample loss for stigmasterol while very minor loss (below $5 \%$ ) was observed for $\delta$-tocopherol. 
Table 4. Matrix effect and recovery studies for delta tocopherol and stigmasterol.

\begin{tabular}{ccccc}
\hline $\begin{array}{c}\text { Concentration } \\
(\mu \mathrm{g} / \mathrm{mL})\end{array}$ & $\begin{array}{c}\text { Delta } \\
\text { Tocopherol }\end{array}$ & Stigmasterol & \\
\cline { 2 - 5 } & Matrix Effect & \%Recovery & Matrix Effect & \%Recovery \\
\hline 0.75 & $108.22 \pm 0.96$ & $104.60 \pm 4.05$ & - & - \\
5.5 & - & $99.94 \pm 1.68$ & - & $95.49 \pm 0.06$ \\
8 & $93.96 \pm 2.1$ & $98.76 \pm 3.72$ & $106.74 \pm 5.8$ & $96.89 \pm 2.03$ \\
\hline
\end{tabular}

\subsubsection{Stability}

Both the benchtop and autosampler QCs used for evaluating stability met the acceptable limits for both accuracy and precision. Thus, the analytes are stable during sample preparation and analysis (Supplementary materials Table S2).

\subsection{Application of the Method for the Quantification of Phytosterols and Tocopherols}

The validated FC-MS method was applied in the quantitative analysis of phytosterols and tocopherols present in the unsaponifiable matter of CODD. For the analyzed samples, the unsaponifiable content in CODD was in the range 26-29\%. Two CODD sources were utilized and they differed in the approach employed during the canola oil pressing process, that is, hot pressed or cold pressed. Thus, a total of three samples were analyzed, namely cold pressed CODD and two different batches from hot pressed CODD. As shown in Table 5 , six bioactives were identified and quantified in all CODD samples. The composition of these bioactives were $\alpha$-, and $\gamma$-tocopherols, brassicasterol, campesterol, stigmasterol, and $\beta$-sitosterol. $\gamma$-tocopherol and $\beta$-sitosterol were the abundant tocopherol and phytosterol, respectively, while $\delta$-tocopherol was not detected. In addition, stigmasterol was only present in very low concentration and phytosterols abundance were as follows; $\beta$-sitosterol $>$ campesterol $>$ brassicasterol $>$ stigmasterol. Phytosterols and tocopherols content in CODD unsaponifiable matter were $30-35 \%$ and $2-4 \%$, respectively. All the samples have similar composition and the differences in quantity can be attributed to variations in cultivar, extraction, and refining procedures.

Table 5. Phytosterols and tocopherols content (\%) in CODD.

\begin{tabular}{cccc}
\hline & Hot Pressed CODD & Hot Pressed CODD & \multirow{2}{*}{ Cold Pressed CODD } \\
\cline { 2 - 3 } & Batch 1 & Batch 2 & \\
\hline Gamma tocopherol & $2.20 \pm 0.02$ & $1.26 \pm 0.14$ & $2.47 \pm 0.17$ \\
Alpha tocopherol & $0.90 \pm 0.01$ & $0.63 \pm 0.01$ & $1.43 \pm 0.01$ \\
Delta tocopherol & nd & nd & nd \\
Brassicasterol & $7.59 \pm 0.13$ & $7.10 \pm 0.14$ & $6.57 \pm 0.21$ \\
Campesterol & $11.24 \pm 0.51$ & $9.75 \pm 0.46$ & $11.93 \pm 0.27$ \\
Stigmasterol & $1.08 \pm 0.10$ & $1.00 \pm 0.03$ & $1.13 \pm 0.18$ \\
3-Sitosterol & $14.73 \pm 0.31$ & $12.03 \pm 0.46$ & $15.68 \pm 0.59$ \\
\hline nd-not detected. & & &
\end{tabular}

The quantification of phytosterols and tocopherols from vegetable oil samples will provide crucial information in determining the ideal sample to use for extracting these bioactives for commercial use. The final utilization of phytosterols and tocopherols requires their purification from the unsaponifiable matter and therefore, information on the composition and their quantity will be informative in designing efficient extraction procedures.

\section{Materials and Methods}

\subsection{Reagents and Chemicals}

$\beta$-sitosterol (Cat. no. S497050), campesterol (Cat. no. C155360), stigmasterol (Cat. no. S686750), brassicasterol (Cat. no. B686750), and $d_{6}$-cholesterol (Cat. no. C432502) at 
98\% purity were purchased from Toronto Research Chemicals (North York, ON, Canada). Cholestanol (Cat. no. D6128) (95\%), $\alpha$-tocopherol (Cat. no. 47783) (99.9\%), $\gamma$-tocopherol (Cat. no. 47785) (96.8\%), $\delta$-tocopherol (Cat. no. 47784) (94\%), chloroform (Cat. no. 366927), methanol (LCMS grade, Cat. no. 106035), acetonitrile (LCMS grade, Cat. no. 100029), hexane (270504) and formic acid (Cat. no. 33015) were purchased from Sigma Aldrich (Oakville, ON, Canada) while 3,4-dihydro-2-methyl-2-(4,8,12-trimethyltridecyl)2H-1-benzopyran-6-ol (rac tocol), Cat. no. ab144067 (95\%) was obtained from Abcam (Toronto, ON, Canada). Canola oil deodorizer distillate (CODD) was obtained from LDM Foods (Yorkton, SK, Canada).

\subsection{Standard Solutions}

Stock solution of reference standard phytosterols and tocopherols were prepared by dissolving each compound at $1 \mathrm{mg} / \mathrm{mL}$ in chloroform. A mixed stock solution containing all 7 standards (phytosterols and tocopherols) was prepared at $50 \mu \mathrm{g} / \mathrm{mL}$ by pipetting the required volume from the stock solution and diluting it with acetonitrile. Similarly, internal standards reference stock solution (cholestanol or $\mathrm{d}_{6}$-cholesterol for phytosterols and rac tocol for tocopherols) were prepared by dissolving each at $1 \mathrm{mg} / \mathrm{mL}$ in chloroform. Note that two different internal standards for phytosterols were evaluated during method development and $\mathrm{d}_{6}$-cholesterol was eventually chosen as it did not cause interferences (see results and discussion). A mixed internal standard working solution of rac tocol and cholestanol or $\mathrm{d}_{6}$-cholesterol was prepared by pipetting the required volume of each analyte and diluting it with acetonitrile for a final concentration of $100 \mu \mathrm{g} / \mathrm{mL}$. Calibration standards in the concentration range $0.05-10 \mu \mathrm{g} / \mathrm{mL}$ were prepared in triplicates in acetonitrile. All internal standards were spiked into each calibrant at a final concentration of $2.5 \mu \mathrm{g} / \mathrm{mL}$. Gamma and beta tocopherols are positional isomers and were not chromatographically resolved. As such, they are quantified collectively, as previously done using gamma tocopherol as reference standard [39,58-60].

\subsection{Sample Preparation \\ Unsaponifiable Matter}

For the preparation of the unsaponifiable matter that contains both phytosterols and tocopherols, previously developed extraction method was adapted [40]. Briefly, $5 \mathrm{~g}$ of CODD was saponified with $1 \mathrm{M} \mathrm{KOH}$ in $95 \%$ ethanol for $1 \mathrm{~h}$ at $65^{\circ} \mathrm{C}$. The mixture was cooled to room temperature and $50 \mathrm{~mL}$ of distilled water was added. Unsaponifiables were extracted three times with $50 \mathrm{~mL}$ hexane and the combined organic phase was washed with $10 \% \mathrm{EtOH}$ to remove excess $\mathrm{KOH}$ until the washings were neutral to phenolphthalein. The organic phase was dried by passing it through anhydrous sodium sulfate followed by evaporation of hexane using a Buchi rotary evaporator R200 (Buchi corp., DE, USA). The residue was further dried under high vacuum using Trivac vacuum D4A (Leybold vacuum products Inc., Export, PA, USA) overnight.

\subsection{HPLC and MS Parameters}

Chromatographic separation of the analytes was performed on an Agilent Acquity UPLC (Agilent Technologies, Mississauga, ON, Canada) system with an Agilent Poroshell guard column $(2.1 \mathrm{~mm} \times 5 \mathrm{~mm}, 2.7 \mu \mathrm{m}$ (Cat. no. 821725-911) and $2.1 \mathrm{~mm} \times 5 \mathrm{~mm}, 1.9 \mu \mathrm{m}$ (Cat. no. 821725-940). Flow rate was investigated in the range $150-800 \mu \mathrm{L} / \mathrm{min}$ and the run times ranged $1.3-2 \mathrm{~min}$. The column temperature was also evaluated in the range $10-20{ }^{\circ} \mathrm{C}$, with better separation achieved at $10^{\circ} \mathrm{C}$. An isocratic elution of acetonitrile: methanol (99:1 $v / v$ ) with $0.03 \%$ acetic acid was used at a flow rate of $200 \mu \mathrm{L} / \mathrm{min}$ and $600 \mu \mathrm{L} / \mathrm{min}$ for $2.7 \mu \mathrm{m}$ and $1.9 \mu \mathrm{m}$ guard column, respectively, and the injection volume was $1.0 \mu \mathrm{L}$.

Detection and quantification were performed using an AB Sciex 6500 QTRAP $^{\circledR}$ quadruple-linear ion trap (QqQ-LIT) mass spectrometer equipped with an atmospheric pressure chemical ionization (APCI) source (AB Sciex, Concord, ON, Canada). The analysis was performed by applying basic scheduled MRM algorithm, and two transitions 
(quantifier and qualifier) were monitored for each compound (Table 2). Tandem mass spectrometric analysis (MS/MS) using APCI was employed in positive ionization as recently optimized [39]. The following interface parameters were used: source temperature $380^{\circ} \mathrm{C}$, curtain gas $25 \mathrm{psi}$, nebulizer current $2.5 \mu \mathrm{A}$, and an ion source gas $130 \mathrm{psi}$. Collision energy (CE) and declustering potential (DP) of each transition were optimized by direct infusion of individual reference standards.

Both instrument control and data acquisition were done using Analyst software 1.7 while data processing and quantification was done using MultiQuant 3.0.3 and applying SignalFinder integration algorithm. The algorithm SignalFinder is based on peak modelling that allows for better integration of poorly resolved peaks. This leads to consistent integration of peaks of interest across the concentration range. Due to the short analysis time, a scheduled MRM (sMRM) was adopted to promote reliability by ensuring enough data points were collected across the chromatographic peak. The target scan time $\left(t_{\text {Target }}\right)$ (i.e., cycle time) was optimized to ensure at least 10 data points across a chromatographic peak were acquired for accurate quantification. A $t_{\text {Target }}$ values in the range $0.3-0.6 \mathrm{~s}$ were evaluated and the value with at least 10 data points and acceptable peak shape was chosen as optimal. To ensure complete monitoring of all transitions, a detection window of $35 \mathrm{~s}$ was chosen. The mass transitions, CE, DP, and retention times of all target compounds including the internal standards are shown in Table 2.

\subsection{Method Validation}

The International Council for Harmonization of Technical Requirements for Pharmaceuticals for Human Use (ICH) guidelines [55] were used to ensure the validity of the method, including linearity, sensitivity, accuracy, precision, repeatability, matrix effects, recovery, and stability. A key challenge, however, is the lack of an analyte free matrix. Both the calibration standards and quality control $(\mathrm{QC})$ samples were prepared in a surrogate matrix that is a neat solvent, namely acetonitrile. A blank matrix containing very low level of endogenous analyte can be used to prepare QC samples during method validation for endogenous metabolites [56]. However, in this study, the concentration of the majority of the analytes were above the middle of the linear range; hence, the choice for a surrogate matrix approach. Exceptions were delta tocopherol (not detected in the matrix) and stigmasterol which was present at relatively low concentrations. Thus, in addition to validation using QCs prepared in neat solvent, both delta tocopherol and stigmasterol QC samples were prepared in the matrix and evaluated, as described in Section 3.5.2.

\subsubsection{Calibration Curve and Sensitivity}

A standard curve for each analyte with at least eight data points in the range $0.05-10 \mu \mathrm{g} / \mathrm{mL}$ was constructed by plotting the peak area ratios (peak area of analyte to that of internal standard) versus the analyte concentration. A least-square regression model with a weighting factor of $1 / x$ was applied. The performance of the standard curve was assessed using coefficient of determination $\left(\mathrm{r}^{2}\right)$ and by evaluating the deviation of standards from nominal concentration. Calibration curve is only accepted when the data points in the curve lies within $\pm 15 \%$ relative standard deviation of nominal value except for lower limit of quantitation (LLOQ) that can be $\pm 20 \%$.

Limit of detection (LOD) was determined based on a signal to noise (S/N) ratio $\geq 3$ while LLOQ was set at the lowest concentration that showed accuracy and precision within $\pm 20 \% \mathrm{CV}$ of the nominal value.

\subsubsection{Intraday and Interday Accuracy and Precision}

To establish intraday and interday accuracy and precision, quality control samples at four concentration levels ((LLOQ, low quality control (LQC), middle quality control (MQC), and high-quality control (HQC)) were analyzed. The LQC was within 3-fold of the LLOQ, the MQC was at the middle point of the standard curve range, and the HQC was within $80 \%$ of the upper limit of quantitation (ULOQ). In the case of stigmasterol, the 
endogenous amount was first determined and MQC and HQC prepared by spiking the matrix with appropriate amount of the standard. The same approach was applied in the case of delta tocopherol; however, it was not detected in the matrix and all QC samples were prepared in the matrix. Accuracy and precision for QC samples should lie within $\pm 15 \%$ CV of nominal value except for LLOQ, which can be within $\pm 20 \% \mathrm{CV}$. Intraday accuracy and precision were calculated using QC replicates $(n=4)$ in a single analytical run whereas interday accuracy and precision measurements were conducted using QC replicates $(n=4)$ prepared on three consecutive days.

\subsubsection{Recovery and Matrix Effect}

For analyte recovery, determination was assessed in the unsaponifiable matter. Quality controls (LQC, MQC, and HQC) were spiked into the unsaponifiable matter and the analyte relative recovery was calculated as shown in Equation (1). Since there are no clear guidelines for recovery experiments for endogenous metabolites where analyte free matrix is not available, the described approach for the determination of recovery was adapted. The endogenous concentration in the matrix was first measured and then QC standards were spiked.

$$
\text { Recovery }(\%)=\frac{\text { Csample spiked-Csample }}{\text { Cspike level }} \times 100
$$

where $\mathrm{C}_{\text {sample spiked }}$ is the measured concentration in spiked sample after extraction, $\mathrm{C}_{\text {sample }}$ is the endogenous concentration in un-spiked sample and $C_{\text {spike level }}$ is the spiked concentration.

For matrix effect, Equation (2) was applied and evaluation was conducted by spiking the unsaponifiable matter at two concentration levels, LQC and HQC. The spiked amount was equivalent to that amount that would bring the $Q C$ to the required concentration with the endogenous amount in consideration.

$$
\text { Matrix effect }(\%)=\frac{\text { Asample spike }}{\text { Aneat }} \times 100
$$

where $A_{\text {sample spike }}$ is peak area of spiked sample, and $A_{\text {neat }}$ is peak area of the same amount in neat solvent.

\subsubsection{Stability}

Benchtop and autosampler stability were evaluated using QC samples prepared in the matrix. $\delta$-tocopherol at LLOQ, LQC, MQC, and HQC and stigmasterol at MQC, and HQC were employed in this study. Benchtop QCs were left at room temperature for $12 \mathrm{~h}$ while autosampler were kept in the autosampler at $10^{\circ} \mathrm{C}$ for $12 \mathrm{~h}$ before analysis.

\section{Application of the Method for the Analysis of Phytosterols and Tocopherols}

The validated method was applied for the determination of phytosterols and tocopherols present in canola oil deodorizer distillate (CODD). CODD is a waste stream from canola oil refining process and is rich in phytosterols and tocopherols. Both phytosterols and tocopherols are present in the unsaponifiable fraction. The unsaponifiable matter of the CODD have been used for the extraction of bioactive metabolites [61] and it is important to measure the concentration of target analytes prior to extraction. For LC-MS/MS analysis, $1 \mathrm{mg} / \mathrm{mL}$ of sample was prepared in chloroform and $50 \mu \mathrm{L}$ was pipetted into an amber HPLC vial, internal standards added, and the contents were diluted to $1 \mathrm{~mL}$ with acetonitrile.

\section{Conclusions}

A fast chromatography-tandem mass spectrometric method (FC-MS/MS) was developed for the quantitative analysis of phytosterols and tocopherols in vegetable oil samples. The reported approach addressed the shortcomings of FIA-MS, where analyte-to-analyte interferences is a major concern. We have shown that application of a guard column with 
smaller particle size is ideal and substantially shortens the run time. The method has a total run time of $1.3 \mathrm{~min}$. Good separation of all the analytes including the ability to differentiate the interfering peaks were achieved. The method was successfully validated and applied in the quantitative determination of phytosterols and tocopherols in CODD. In addition, this method can be used as starting point for the development of qualitative and quantitative analysis of the purified phytosterols and tocopherols, after extracting them from the unsaponifiable matter. This analytical method can also be applied for the quantification of phytosterols and tocopherols in other vegetable oil sources, such as corn, sunflower, soybean, and olive. It can also be the basis for the development of quantitative methods in pharmaceutical formulations, supplements, and beverages. However, appropriate sample preparation should be adopted, and the method will require optimization for the intended purpose.

Supplementary Materials: The following are available online. Table S1: Summary for some reported studies outlining analyte-to-analyte interferences for the analysis of plant sterols, Table S2: Benchtop and autosampler stability in matrix spiked QCs shown as mean \pm SD, Figure S1: Cholestanol as an internal standard showed analyte interferences, where insert chromatograms shown by $\rightarrow$ is extracted ion chromatogram for brassicasterol and $\rightarrow$ for campesterol, Figure S2: Cholestanol interfering ion at $m / z 383$ shows a similar MS/MS spectrum as that of campesterol monitored ion $\left[\mathrm{M}+\mathrm{H}-\mathrm{H}_{2} \mathrm{O}\right]^{+}$at $m / z 383$, Figure S3: Brassicasterol MS/MS of interfering ion $[\mathrm{M}+\mathrm{H}-4 \mathrm{H}]^{+}$at $m / z 395$ showing similar MS/MS spectrum as that of Stigmasterol monitored ion $\left[\mathrm{M}+\mathrm{H}-\mathrm{H}_{2} \mathrm{O}\right]^{+}$ at $m / z$ 395, Figure S4: Campesterol MS/MS of interfering ion $[\mathrm{M}+\mathrm{H}-4 \mathrm{H}]^{+}$at $m / z 397$ showing similar MS/MS spectrum as that of $\beta$-sitosterol monitored ion $\left[\mathrm{M}+\mathrm{H}-\mathrm{H}_{2} \mathrm{O}\right]^{+}$at $m / z 397$, Figure S5: Merging of the interfering peak from campesterol $m / z$ 397 $\rightarrow 161 / 135$ with $\beta$-sitosterol peak at high concentration (using $2.7 \mu \mathrm{m}$ guard column), Figure S6: Campesterol $(\mathrm{m} / \mathrm{z} 383 \rightarrow 161 / 147)$ interference peak (insert) from $\mathrm{d}_{6}$-cholesterol, Figure S7: Interfering peaks are distinguishable at both low (A1, A2) and high (B1, B2) concentration when $1.9 \mu \mathrm{m}$ guard column was employed, Figure S8: Calibration curves for tocopherols (A) and phytosterols (B).

Author Contributions: Conceptualization, A.E.-A., and G.G.; methodology, G.G., A.D., and A.P.; software, G.G., A.D., and A.P.; validation, G.G., A.D., and A.E.-A.; formal analysis, G.G., A.E.-A., and A.D.; investigation, G.G., A.D., and A.E.-A.; resources, A.E.-A.; data curation, G.G.; writingoriginal draft preparation, G.G.; writing—review and editing, G.G., A.D., A.P., Z.D.B., and A.E.-A.; visualization, A.E.-A., and G.G.; supervision, A.E.-A., and Z.D.B.; project administration, A.E.-A.; funding acquisition, A.E.-A., Z.D.B. and G.G. All authors have read and agreed to the published version of the manuscript.

Funding: This research was funded by Agriculture Development Fund, Ministry of Agriculture, Government of Saskatchewan, grant number 20150216.

Data Availability Statement: The data presented in this study are available in the above manuscript and its supporting information.

Acknowledgments: The authors acknowledge technical help from Deborah Michel. The authors are thankful to funding from Agriculture Development Fund, Ministry of Agriculture, Government of Saskatchewan. QTRAP 6500 mass spectrometer was funded by Western Diversification Canada grant.

Conflicts of Interest: The authors declare no conflict of interest. The funders had no role in the design of the study; in the collection, analyses, or interpretation of data; in the writing of the manuscript, or in the decision to publish the results.

Sample Availability: Samples of the compounds are available from the authors.

\section{References}

1. $\quad$ Eussen, S.R.; de Jong, N.; Rompelberg, C.J.; Garssen, J.; Verschuren, W.M.; Klungel, O.H. Dose-dependent cholesterol-lowering effects of phytosterol/phytostanol-enriched margarine in statin users and statin non-users under free-living conditions. Public Health Nutr. 2011, 14, 1823-1832. [CrossRef] [PubMed]

2. Trautwein, E.A.; Demonty, I. Phytosterols: Natural compounds with established and emerging health benefits. Oléagineux Corps gras Lipides 2007, 14, 259-266. [CrossRef] 
3. Frei, B. Reactive oxygen species and antioxidant vitamins: Mechanisms of action. Am. J. Med. 1994, 97, S5-S13. [CrossRef]

4. Rowlands, J.C.; Hoadley, J.E. Fda perspectives on health claims for food labels. Toxicology 2006, 221, 35-43. [CrossRef]

5. Commission Regulation (EC), No. 608/2004 concerning the labelling of foods and food ingredients with added phytosterols, phytosterol esters, phytostanols and/or phytostanol (Text with EEA relevance). Off. J. L 2013, 201, 49-50.

6. Verleyen, T.; Verhé, R.; Garcia, L.; Dewettinck, K.; Huyghebaert, A.; De Greyt, W. Gas chromatographic characterization of vegetable oil deodorization distillate. J. Chromatogr. A 2001, 921, 277-285. [CrossRef]

7. Xu, B.; You, S.; Zhou, L.; Kang, H.; Luo, D.; Ma, H.; Han, S. Simultaneous determination of free phytosterols and tocopherols in vegetable oils by an improved SPE-GC-FID method. Food Anal. Methods 2020, 13, 358-369. [CrossRef]

8. Mohamed, H.; Awatif, I. The use of sesame oil unsaponifiable matter as a natural antioxidant. Food Chem. 1998, 62, 269-276. [CrossRef]

9. Kasim, N.S.; Gunawan, S.; Yuliana, M.; Ju, Y.-H. A simple two-step method for simultaneous isolation of tocopherols and free phytosterols from soybean oil deodorizer distillate with high purity and recovery. Sep. Sci. Technol. 2010, 45, 2437-2446. [CrossRef]

10. Raja Rajan, R.; Gopala Krishna, A. A simple method for purification of deodorizer distillate from indian rice (oryza sativa) bran oil and preparation of phytosterols. Grasas y Aceites 2014, 65, e050.

11. Schott, H.-F.; Krautbauer, S.; Höring, M.; Liebisch, G.; Matysik, S. A validated, fast method for quantification of sterols and gut microbiome derived $5 \alpha / \beta$-stanols in human feces by isotope dilution LC-high-resolution MS. Anal. Chem. 2018, 90, 8487-8494. [CrossRef] [PubMed]

12. Holder, C.; Adams, A.; McGahee, E.; Xia, B.; Blount, B.C.; Wang, L. High-throughput and sensitive analysis of free and total 8-isoprostane in urine with isotope-dilution liquid chromatography-tandem mass spectrometry. ACS Omega 2020, 5, 10919-10926. [CrossRef] [PubMed]

13. Beldean-Galea, M.S.; Horga, C.; Coman, M.V. Separation and determination of tocopherols in vegetable oils by solid phase extraction on porous polymers spe cartridges and capillary gas chromatography analysis. Cent. Eur. J. Chem. 2010, 8, 1110-1116. [CrossRef]

14. dos Santos, M.; Roehrs, M.; de Pereira, C.; Freitag, B.; de Bairros, A. Analysis of phytosterols in plants and derived products by gas chromatography-A short critical review. Austin Chromatogr. 2014, 1, 1-4.

15. Pyka, A.; Sliwiok, J. Chromatographic separation of tocopherols. J. Chromatogr. A 2001, 935, 71-76. [CrossRef]

16. Lechner, M.; Reiter, B.; Lorbeer, E. Determination of tocopherols and sterols in vegetable oils by solid-phase extraction and subsequent capillary gas chromatographic analysis. J. Chromatogr. A 1999, 857, 231-238. [CrossRef]

17. Fernández-Cuesta, Á.; Aguirre-González, M.R.; Ruiz-Méndez, M.V.; Velasco, L. Validation of a method for the analysis of phytosterols in sunflower seeds. Eur. J. Lipid Sci. Technol. 2012, 114, 325-331. [CrossRef]

18. Du, M.; Ahn, D. Simultaneous analysis of tocopherols, cholesterol, and phytosterols using gas chromatography. J. Food Sci. 2002, 67, 1696-1700. [CrossRef]

19. García-Llatas, G.; Vidal, C.; Cilla, A.; Barberá, R.; Lagarda, M.J. Simultaneous quantification of serum phytosterols and cholesterol precursors using a simple gas chromatographic method. Eur. J. Lipid Sci. Technol. 2012, 114, 520-526. [CrossRef]

20. Santos, R.; Limas, E.; Sousa, M.; da Conceição Castilho, M.; Ramos, F.; da Silveira, M.I.N. Optimization of analytical procedures for GC-MS determination of phytosterols and phytostanols in enriched milk and yoghurt. Food Chem. 2007, 102, 113-117. [CrossRef]

21. Ahmida, H.M.; Bertucci, P.; Franzò, L.; Massoud, R.; Cortese, C.; Lala, A.; Federici, G. Simultaneous determination of plasmatic phytosterols and cholesterol precursors using gas chromatography-mass spectrometry (GC-MS) with selective ion monitoring (sim). J. Chromatogr. B 2006, 842, 43-47. [CrossRef] [PubMed]

22. Bartosińska, E.; Buszewska-Forajta, M.; Siluk, D. GC-MS and LC-MS approaches for determination of tocopherols and tocotrienols in biological and food matrices. J. Pharm. Biomed. Anal. 2016, 127, 156-169. [CrossRef]

23. Zuba, D.; Adamowicz, P. Distinction of constitutional isomers of mephedrone by chromatographic and spectrometric methods. Aust. J. Forensic Sci. 2017, 49, 637-649. [CrossRef]

24. Zhu, L.; Yang, S.; Li, G.; Zhang, X.; Yang, J.; Lai, X.; Yang, G. Simultaneous analysis of tocopherols, tocotrienols, phospholipids, $\gamma$-oryzanols and $\beta$-carotene in rice by ultra-high performance liquid chromatography coupled to a linear ion trap-orbitrap mass spectrometer. Anal. Methods 2016, 8, 5628-5637. [CrossRef]

25. Carretero, A.S.; Carrasco-Pancorbo, A.; Cortacero, S.; Gori, A.; Cerretani, L.; Fernández-Gutiérrez, A. A simplified method for HPLC-MS analysis of sterols in vegetable oil. Eur. J. Lipid Sci. Technol. 2008, 110, 1142-1149. [CrossRef]

26. Flakelar, C.L.; Prenzler, P.D.; Luckett, D.J.; Howitt, J.A.; Doran, G. A rapid method for the simultaneous quantification of the major tocopherols, carotenoids, free and esterified sterols in canola (brassica napus) oil using normal phase liquid chromatography. Food Chem. 2017, 214, 147-155. [CrossRef]

27. Cañabate-Díaz, B.; Carretero, A.S.; Fernández-Gutiérrez, A.; Vega, A.B.; Frenich, A.G.; Vidal, J.L.M.; Martos, J.D. Separation and determination of sterols in olive oil by HPLC-MS. Food Chem. 2007, 102, 593-598. [CrossRef]

28. Baila-Rueda, L.; Cenarro, A.; Cofán, M.; Orera, I.; Barcelo-Batllori, S.; Pocoví, M.; Ros, E.; Civeira, F.; Nerín, C.; Domeño, C. Simultaneous determination of oxysterols, phytosterols and cholesterol precursors by high performance liquid chromatography tandem mass spectrometry in human serum. Anal. Methods 2013, 5, 2249-2257. [CrossRef] 
29. Lanina, S.A.; Toledo, P.; Sampels, S.; Kamal-Eldin, A.; Jastrebova, J.A. Comparison of reversed-phase liquid chromatography-mass spectrometry with electrospray and atmospheric pressure chemical ionization for analysis of dietary tocopherols. J. Chromatogr. A 2007, 1157, 159-170. [CrossRef]

30. Huang, L.; Zhong, T.; Chen, T.; Ye, Z.; Chen, G. Identification of $\beta$-sitosterol, stigmasterol and ergosterin in a. Roxburghii using supercritical fluid extraction followed by liquid chromatography/atmospheric pressure chemical ionization ion trap mass spectrometry. Rapid Commun. Mass Spectrom. 2007, 21, 3024-3032. [CrossRef]

31. Varga, M.; Bartók, T.; Mesterházy, Á. Determination of ergosterol in fusarium-infected wheat by liquid chromatographyatmospheric pressure photoionization mass spectrometry. J. Chromatogr. A 2006, 1103, 278-283. [CrossRef]

32. Lauridsen, C.; Leonard, S.; Griffin, D.; Liebler, D.; McClure, T.; Traber, M. Quantitative analysis by liquid chromatographytandem mass spectrometry of deuterium-labeled and unlabeled vitamin e in biological samples. Anal. Biochem. 2001, 289, 89-95. [CrossRef] [PubMed]

33. Kalman, A.; Mujahid, C.; Mottier, P.; Heudi, O. Determination of $\alpha$-tocopherol in infant foods by liquid chromatography combined with atmospheric pressure chemical ionisation mass spectrometry. Rapid Commun. Mass Spectrom. 2003, 17, 723-727. [CrossRef] [PubMed]

34. Zarrouk, W.; Carrasco-Pancorbo, A.; Segura-Carretero, A.; Fernandez-Gutierrez, A.; Zarrouk, M. Exploratory characterization of the unsaponifiable fraction of tunisian virgin olive oils by a global approach with HPLC-APCI-IT MS/MS analysis. J. Agric. Food Chem. 2010, 58, 6418-6426. [CrossRef] [PubMed]

35. Wong, Y.F.; Makahleh, A.; Saad, B.; Ibrahim, M.N.M.; Rahim, A.A.; Brosse, N. Uplc method for the determination of vitamin e homologues and derivatives in vegetable oils, margarines and supplement capsules using pentafluorophenyl column. Talanta 2014, 130, 299-306. [CrossRef]

36. Grebenstein, N.; Frank, J. Rapid baseline-separation of all eight tocopherols and tocotrienols by reversed-phase liquidchromatography with a solid-core pentafluorophenyl column and their sensitive quantification in plasma and liver. J. Chromatogr. A 2012, 1243, 39-46. [CrossRef] [PubMed]

37. Decloedt, A.; Van Landschoot, A.; Watson, H.; Vanderputten, D.; Vanhaecke, L. Plant-based beverages as good sources of free and glycosidic plant sterols. Nutrients 2018, 10, 21. [CrossRef] [PubMed]

38. Bataglion, G.A.; Meurer, E.; de Albergaria-Barbosa, A.C.R.; Bícego, M.C.; Weber, R.R.; Eberlin, M.N. Determination of geochemically important sterols and triterpenols in sediments using ultrahigh-performance liquid chromatography tandem mass spectrometry (UHPLC-MS/MS). Anal. Chem. 2015, 87, 7771-7778. [CrossRef]

39. Poudel, A.; Gachumi, G.; Badea, I.; Bashi, Z.D.; El-Aneed, A. The simultaneous quantification of phytosterols and tocopherols in liposomal formulations using validated atmospheric pressure chemical ionization-liquid chromatography-tandem mass spectrometry. J. Pharm. Biomed. Anal. 2020, 183, 113104. [CrossRef]

40. Jiang, K.; Gachumi, G.; Poudel, A.; Shurmer, B.; Bashi, Z.; El-Aneed, A. The establishment of tandem mass spectrometric fingerprints of phytosterols and tocopherols and the development of targeted profiling strategies in vegetable oils. J. Am. Soc. Mass Spectrom. 2019, 30, 1700-1712. [CrossRef]

41. Mohammed-Saeid, W.; Michel, D.; Badea, I.; El-Aneed, A. Rapid and simple flow injection analysis tandem mass spectrometric method for the quantification of melphalan in a lipid-based drug delivery system. Rapid Commun. Mass Spectrom. 2017, 31, 1481-1490. [CrossRef]

42. Michel, D.; Gaunt, M.C.; Arnason, T.; El-Aneed, A. Development and validation of fast and simple flow injection analysis-tandem mass spectrometry (FIA-MS/MS) for the determination of metformin in dog serum. J. Pharm. Biomed. Anal. 2015, 107, $229-235$. [CrossRef]

43. Nanita, S.C.; Kaldon, L.G. Emerging flow injection mass spectrometry methods for high-throughput quantitative analysis. Anal. Bioanal. Chem. 2016, 408, 23-33. [CrossRef]

44. Gachumi, G.N.; Purves, R.W.; Hopf, C.; El-Aneed, A. Fast quantification without conventional chromatography, the growing power of mass spectrometry. Anal. Chem. 2020, 92, 8628-8637. [CrossRef]

45. Vogeser, M.; Seger, C. Pitfalls associated with the use of liquid chromatography-tandem mass spectrometry in the clinical laboratory. Clin. Chem. 2010, 56, 1234-1244. [CrossRef] [PubMed]

46. Nischwitz, V.; Pergantis, S.A. Optimisation of an hplc selected reaction monitoring electrospray tandem mass spectrometry method for the detection of 50 arsenic species. J. Anal. At. Spectrom. 2006, 21, 1277-1286. [CrossRef]

47. Song, F. "Cross-talk" in scheduled multiple reaction monitoring caused by in-source fragmentation in herbicide screening with liquid chromatography electrospray tandem mass spectrometry. J. Agric. Food Chem. 2011, 59, 4361-4364. [CrossRef] [PubMed]

48. Bedner, M.; Schantz, M.M.; Sander, L.C.; Sharpless, K.E. Development of liquid chromatographic methods for the determination of phytosterols in standard reference materials containing saw palmetto. J. Chromatogr. A 2008, 1192, 74-80. [CrossRef] [PubMed]

49. Ishida, N. A method for simultaneous analysis of phytosterols and phytosterol esters in tobacco leaves using non aqueous reversed phase chromatography and atmospheric pressure chemical ionization mass spectrometry detector. J. Chromatogr. A 2014, 1340, 99-108. [CrossRef]

50. Sánchez-Machado, D.; López-Hernández, J.; Paseiro-Losada, P.; López-Cervantes, J. An HPLC method for the quantification of sterols in edible seaweeds. Biomed. Chromatogr. 2004, 18, 183-190. [CrossRef] 
51. Rozenberg, R.; Ruibal-Mendieta, N.L.; Petitjean, G.; Cani, P.; Delacroix, D.L.; Delzenne, N.M.; Meurens, M.; Quetin-Leclercq, J.; Habib-Jiwan, J.-L. Phytosterol analysis and characterization in spelt (Triticum aestivum ssp. spelta 1.) and wheat (T. aestivum L.) lipids by LC/APCI-MS. J. Cereal Sci. 2003, 38, 189-197. [CrossRef]

52. Buse, J.; Purves, R.W.; Verrall, R.E.; Badea, I.; Zhang, H.; Mulligan, C.C.; Peru, K.M.; Bailey, J.; Headley, J.V.; El-Aneed, A. The development and assessment of high-throughput mass spectrometry-based methods for the quantification of a nanoparticle drug delivery agent in cellular lysate. J. Mass Spectrom. 2014, 49, 1171-1180. [CrossRef]

53. Samanidou, V.F. Basic LC method development and optimization. Anal. Sep. Sci. 2015, 1, $25-42$.

54. Song, W.; Pabbisetty, D.; Groeber, E.A.; Steenwyk, R.C.; Fast, D.M. Comparison of fused-core and conventional particle size columns by LC-MS/MS and UV: Application to pharmacokinetic study. J. Pharm. Biomed. Anal. 2009, 50, 491-500. [CrossRef]

55. Guideline, I.H.T. Validation of Analytical Procedures: Text and Methodology Q2 (R1); International Conference on Harmonization: Geneva, Switzerland, 2005; pp. 11-12.

56. Guideline, I.H. M10 Bioanalytical Method Validation; Center for Drug Evaluation and Research: Rockville, MD, USA, 2019.

57. Khamis, M.M.; Adamko, D.J.; El-Aneed, A. Strategies and challenges in method development and validation for the absolute quantification of endogenous biomarker metabolites using liquid chromatography-tandem mass spectrometry. Mass Spectrom. Rev. 2019, 40, 31-52. [CrossRef] [PubMed]

58. Poudel, A.; Gachumi, G.; Wasan, K.M.; Dallal Bashi, Z.; El-Aneed, A.; Badea, I. Development and characterization of liposomal formulations containing phytosterols extracted from canola oil deodorizer distillate along with tocopherols as food additives. Pharmaceutics 2019, 11, 185. [CrossRef] [PubMed]

59. Kornsteiner, M.; Wagner, K.-H.; Elmadfa, I. Tocopherols and total phenolics in 10 different nut types. Food Chem. 2006, 98, 381-387. [CrossRef]

60. Zarrouk, W.; Carrasco-Pancorbo, A.; Zarrouk, M.; Segura-Carretero, A.; Fernández-Gutiérrez, A. Multi-component analysis (sterols, tocopherols and triterpenic dialcohols) of the unsaponifiable fraction of vegetable oils by liquid chromatographyatmospheric pressure chemical ionization-ion trap mass spectrometry. Talanta 2009, 80, 924-934. [CrossRef]

61. Ghazani, S.M.; García-Llatas, G.; Marangoni, A.G. Micronutrient content of cold-pressed, hot-pressed, solvent extracted and rbd canola oil: Implications for nutrition and quality. Eur. J. Lipid Sci. Technol. 2014, 116, 380-387. [CrossRef] 